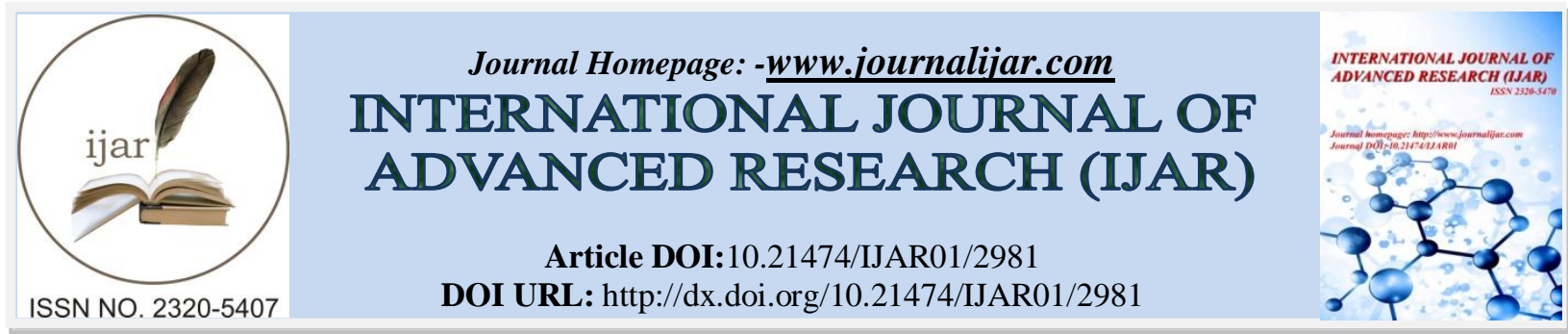

RESEARCH ARTICLE

\title{
INCIDENCE OF NOSOCOMIAL BLOOD STREAM INFECTION, PNEUMONIA AND URINARY TRACT INFECTION INPEDIATRIC WARD AT KING ABDULAZIZ UNIVERSITY HOSPITAL, JEDDAH, SAUDI ARABIA 2015- 2016.
}
Osama Y. Safder, Mohammed S. Alzahrani, Wafaa F. Alharbi, Hassan K. Balubaid, Mohammed F. Bukhari, Bashaer S. Alshomrany, Barah A. Malibari, Nada J. Alata, Manayer G. ALmutairi and AbeerAlnajjar.

\section{Manuscript Info}

\section{Manuscript History}

Received: 26 November 2016

Final Accepted: 27 December 2016

Published: January 2017

\section{Abstract}

Background: Nosocomial infections (NI): "defined as those occurring within 48 hours of hospital admission, 3 days of discharge or 30 days of an operation". NI is Major complication in pediatric patients at different hospital wards. NI is associated with significant morbidity and mortality. Studies had shown that NI are associated with prolonged hospital stay and increase economic burden on the health care system. Objectives:-Identify the commonest organism which causes nosocomial BSI, pneumonia or UTI among pediatric patients at KAUH,2015-2016.To-know the prevalence of nosocomial BSI, pneumonia and UTI among pediatric patients atKAUH,2015-2016.Identify the commonest predisposing factors which lead to nosocomial BSI, pneumonia and UTI among pediatric patients at KAUH,20152016.

Methods:This is a retrospective study done at King Abdulaziz University Hospital Jeddah Saudi Arabia 2015-2016.This include all pediatric patients who developed fever after 48 hours of hospital admission, 3days of discharge or 30 days of an operation in pediatric ward 2015-1016.

Results:The number of patients who admitted was 1502 patients, 111 patients got NI. Infants are more reliable to have NI by(62.2\%).Patient who had cardiovascular disease(18.9\%)is more susceptible to have NI. The commonest type of infections were UTI(25.2\%), BSI(21.6\%) and pneumonia(19.8\%).Gram negative were the dominant(48.9\%).The commonest pathogen was Coagulase negative staphylococci(25.3\%).The most predisposing factors were Immunosuppressive medications(22.5\%),Central venous catheter(22.5\%)and Nasogastric tube (19.8\%).

Conclusions: Infant patients are more reliable to get NI. The UTI is the commonest type of infection. Gram negative are the commonest but, the Coagulase negative staphylococci is the common organism. Immunosuppressive medications, Central venous catheter and Nasogastric tube are the most predisposing factors.

Copy Right, IJAR, 2016,. All rights reserved. 


\section{Introduction:-}

Nosocomial infections (NI): "defined as those occurring within 48 hours of hospital admission, 3 days of discharge or 30 days of an operation" (1). NI are a Major complication in pediatric patients at different hospital wards. NI are associated with significant morbidity and mortality. Studies had shown that nosocomial infection is strongly associated with prolonged hospital stay and increase the economic burden on the health care system (2). Many studies had shown that the most common organisms are gram-negative bacteria as Klebsiella pneumonia, E-coli, and pseudomonas aeruginosa, followed by gram positive bacteria as staphylococcus aureus, and enterococci (3). The most common type of infections are blood stream infection, followed by pneumonia, and UTI(4). There are multiple risk factors that precipitate NI as prolonged hospital stay, and patients who are admitted to ICU are more prone to have NI (5). Patients who are on mechanical ventilation device, central venous line, or urinary catheter are at higher risk to develop NI. (6) In Tunisia, a prospective cohort study was done and showed over all incidence of NI is (6.5\%), mostly caused by Gram-negative bacteria (68\%) with Klebsiella pneumonia accounting (22.7\%), the commonest type is BSI (7). On the other hand, in a multicenter European prospective study showed that the overall incidence of NI is (2.5\%), mostly caused by bacteria accounting for (68\%). Most of these bacteria are gram negative bacilli but, that coagulase negative staphylococcus is the main pathogen. The same study showed that antibiotic resistant was highest in PICU compared to the general pediatric unit. (8) Locally, at Al-Hada Armed Forces Hospital in Taif, Saudi Arabia during the year 2004. A prospective study was for all patients admitted there. The most common site of infection was pneumonia (32.3\%), followed by urinary tract infection (UTI) (25.7\%) and blood stream infections (BSI) (18.6\%). The most common organism was Gram negative (66.2\%). E.coli was the most common organism (22.3\%) (9).

\section{Research objectives:-}

1. Identify the most common organism which causes nosocomial blood stream infection, pneumonia or Urinary tract infection among pediatric patients at KAUH,2015-2016.

2. To know the prevalence of nosocomial blood stream infection, pneumonia and Urinary tract infection among pediatric patients at KAUH,2015-2016.

3. Identify the most common predisposing factors which lead to nosocomial blood stream infection, pneumonia and Urinary tract infection among pediatric patients at KAUH,2015-2016.

\section{Research Methodology:-}

This is a retrospective observational study done at KAUH, Jeddah, Saudi Arabia 2015-2016.

This include all pediatric patient who admitted to the pediatric ward between 15 February 2015 to 16 February 2016

Inclusion criteria: "infection thant occurring within 48 hours of hospital admission, 3 days of discharge or 30 days of an operation" (1).

Statistical analysis:In the present study, statistical analysis using "IBM SPSS statistics ver. 20.0" was applied to evaluate and test the hypothesis.

Descriptive statistics, charts (Frequencies and percentage ).

study tools: a data gathered by hospital system using a data sheet with include demographics, date of admission, date of discharge, comorbidity, diagnosis, length of stay, investigation (on admission, with infection, after infection)

imaging, medication, risk factor(blood transfusion, immunosuppressant medication, stress ulcer prophylaxis ,central line, PICC line, NGT, TPN, urinary catheter, ventilator, tracheostomy ), outcome.

\section{Results:-}

The total number of patients who admitted between 15 February 2015 to 16 February 2016 was 1502 patients, 111 patients got a nosocomial infection.

Among the different age groups, the Infants are more reliable to have a nosocomial infection by $(62.2 \%)$. The patient who had an underlying cardiovascular disease (18.9\%) are more susceptible to has a nosocomial infection, followed 
by a neurological disease (16.2\%) and gastrointestinal disease (16.2\%). The most common type of infections in this study was UTI (25.2\%) followed by blood stream infection (21.6\%), pneumonia (19.8\%).

Gram-negative organisms were the dominant by (48.9\%). gram positive caused (43.3\%), fungi caused (7.8\%) .

The most common pathogen was Coagulase-negative staphylococci (25.3\%), followed by pseudomonas aeruginosa $(14.5 \%)$ and Enterococcus faecalis (7.2\%).

The three most potential predisposing factors were Immunosuppressive medications ( $22.5 \%$ ), Central venous catheter $(22.5 \%)$ and Nasogastric tube (19.8\%). This study also showed that increase length of stay may increase the chance to get a nosocomial infection.

The majority of patients recovered within one week (57.7\%). the mortality were only (3.6\%).

Table 1:- Distribution of pediatric age groups

\begin{tabular}{|c|c|c|}
\hline \multicolumn{2}{|c|}{ Age } \\
\hline Frequency & Percent \\
\hline Infant & 69 & 62.2 \\
\hline Up to 10 years & 30 & 27.0 \\
\hline Above 10 years & 12 & 10.8 \\
\hline Total & 111 & 100.0 \\
\hline
\end{tabular}

Table 2:- Underlying disease of all Pediatric patients who developed NI

\begin{tabular}{|l|l|l|l|l|}
\hline \multirow{2}{*}{} & Yes & No & \\
\cline { 2 - 5 } & Count & Table N \% & Count & Table N \% \\
\hline Cardiovascular diseases & 21 & $18.9 \%$ & 90 & $81.1 \%$ \\
\hline Neurology diseases & 18 & $16.2 \%$ & 93 & $83.8 \%$ \\
\hline GI diseases & 18 & $16.2 \%$ & 93 & $83.8 \%$ \\
\hline Respiratory diseases & 14 & $12.6 \%$ & 97 & $87.4 \%$ \\
\hline Hematology diseases & 10 & $9.0 \%$ & 101 & $91.0 \%$ \\
\hline Oncology diseases & 10 & $9.0 \%$ & 101 & $91.0 \%$ \\
\hline Renal diseases & 8 & $7.2 \%$ & 103 & $92.8 \%$ \\
\hline Genetics diseases & 7 & $6.3 \%$ & 104 & $93.7 \%$ \\
\hline Endocrine diseases & 6 & $5.4 \%$ & 105 & $94.6 \%$ \\
\hline Infectious diseases & 5 & $4.5 \%$ & 106 & $95.5 \%$ \\
\hline
\end{tabular}

Table 3:- Results of all cultures done for all Pediatric patients who developed NI

\begin{tabular}{|c|c|c|}
\hline \multicolumn{3}{|c|}{ Urine Culture } \\
\hline & Frequency & Percent \\
\hline Positive & 28 & 25.2 \\
\hline Negative & 47 & 42.3 \\
\hline No culture & 36 & 32.4 \\
\hline Total & 111 & 100.0 \\
\hline \multicolumn{3}{|c|}{ Blood culture } \\
\hline & Frequency & Percent \\
\hline Positive & 24 & 19.8 \\
\hline Negative & 67 & 60.4 \\
\hline No culture & 22 & 19.8 \\
\hline Total & 111 & 100.0 \\
\hline \multicolumn{3}{|c|}{ Respiratory culture } \\
\hline & Frequency & Percent \\
\hline Positive & 22 & 19.8 \\
\hline Negative & 20 & 18 \\
\hline No culture & 69 & 62.2 \\
\hline Total & 111 & 100.0 \\
\hline
\end{tabular}


Table 4:- Result of Positive cultures

\begin{tabular}{|l|l|l|}
\hline & Frequency & Percent \\
\hline Gram negative & 44 & 48.9 \\
\hline Gram positive & 39 & 43.3 \\
\hline Fungus & 7 & 7.8 \\
\hline Total & 90 & 100 \\
\hline
\end{tabular}

Table 5:- Causative bacterial Organisms

\begin{tabular}{|c|c|c|}
\hline \multicolumn{3}{|l|}{ Organism } \\
\hline & Frequency & Percent \\
\hline coagulase negative staph & 21 & 25.3 \\
\hline pseudumonasaeruginosa & 12 & 14.5 \\
\hline Enterococcus faecalis & 6 & 7.2 \\
\hline Enterobacter cloacae & 5 & 6.0 \\
\hline ESBL positive e.coli & 5 & 6.0 \\
\hline acinetobacterbaumannii & 4 & 4.8 \\
\hline E.coli & 4 & 4.8 \\
\hline stenotrophomonasmaltophilia & 3 & 3.6 \\
\hline streptococcus viridans & 3 & 3.6 \\
\hline ESBL positive klebisiella pneumonia & 3 & 3.6 \\
\hline Klebsiella pneumonia & 3 & 3.6 \\
\hline Enterococcus faecium van a vre & 2 & 2.4 \\
\hline MRSA & 2 & 2.4 \\
\hline Gram negative bacilli & 2 & 2.4 \\
\hline Staphylococcus hominis & 1 & 1.2 \\
\hline serratiamacescens & 1 & 1.2 \\
\hline dermacoccusnishinomiyaensis & 1 & 1.2 \\
\hline citrobacteramalonaticus & 1 & 1.2 \\
\hline Staphylococcus epidermidis & 1 & 1.2 \\
\hline Citrobacterkoseri & 1 & 1.2 \\
\hline streptococcus pnemoniae & 1 & 1.2 \\
\hline Streptococcus salivaris & 1 & 1.2 \\
\hline Total & 83 & 100.0 \\
\hline
\end{tabular}

Table 6:- Foreign bodies associated with NI

\begin{tabular}{|c|c|c|}
\hline \multicolumn{3}{|c|}{ Central venous catheter } \\
\hline & Frequency & Percent \\
\hline Yes & 25 & 22.5 \\
\hline No & 86 & 77.5 \\
\hline Total & 111 & 100.0 \\
\hline \multicolumn{3}{|c|}{ Peripherally inserted catheter } \\
\hline & Frequency & Percent \\
\hline Yes & 18 & 16.2 \\
\hline No & 93 & 83.8 \\
\hline Total & 111 & 100.0 \\
\hline \multicolumn{3}{|l|}{ Nasogastric tube } \\
\hline & Frequency & Percent \\
\hline Yes & 22 & 19.8 \\
\hline No & 89 & 80.2 \\
\hline \begin{tabular}{l|l|}
\cline { 2 - 2 } & Total \\
\end{tabular} & 111 & 100.0 \\
\hline \multicolumn{3}{|l|}{ Tracheostomy } \\
\hline & Frequency & Percent \\
\hline Yes & 8 & 7.2 \\
\hline
\end{tabular}




\begin{tabular}{|c|c|c|}
\hline No & 103 & 92.8 \\
\hline Total & 111 & 100.0 \\
\hline \multicolumn{3}{|c|}{ Mechanical ventilator } \\
\hline & Frequency & Percent \\
\hline Yes & 14 & 12.6 \\
\hline No & 97 & 87.4 \\
\hline Total & 111 & 100.0 \\
\hline \multicolumn{3}{|l|}{ Foley Catheter } \\
\hline & Frequency & Percent \\
\hline Yes & 11 & 9.9 \\
\hline No & 100 & 90.1 \\
\hline Total & 111 & 100.0 \\
\hline \multicolumn{3}{|l|}{ Parenteral Nutrition } \\
\hline & Frequency & Percent \\
\hline Yes & 16 & 14.4 \\
\hline No & 95 & 85.6 \\
\hline Total & 111 & 100.0 \\
\hline
\end{tabular}

Table 7:- treatment associated with NI

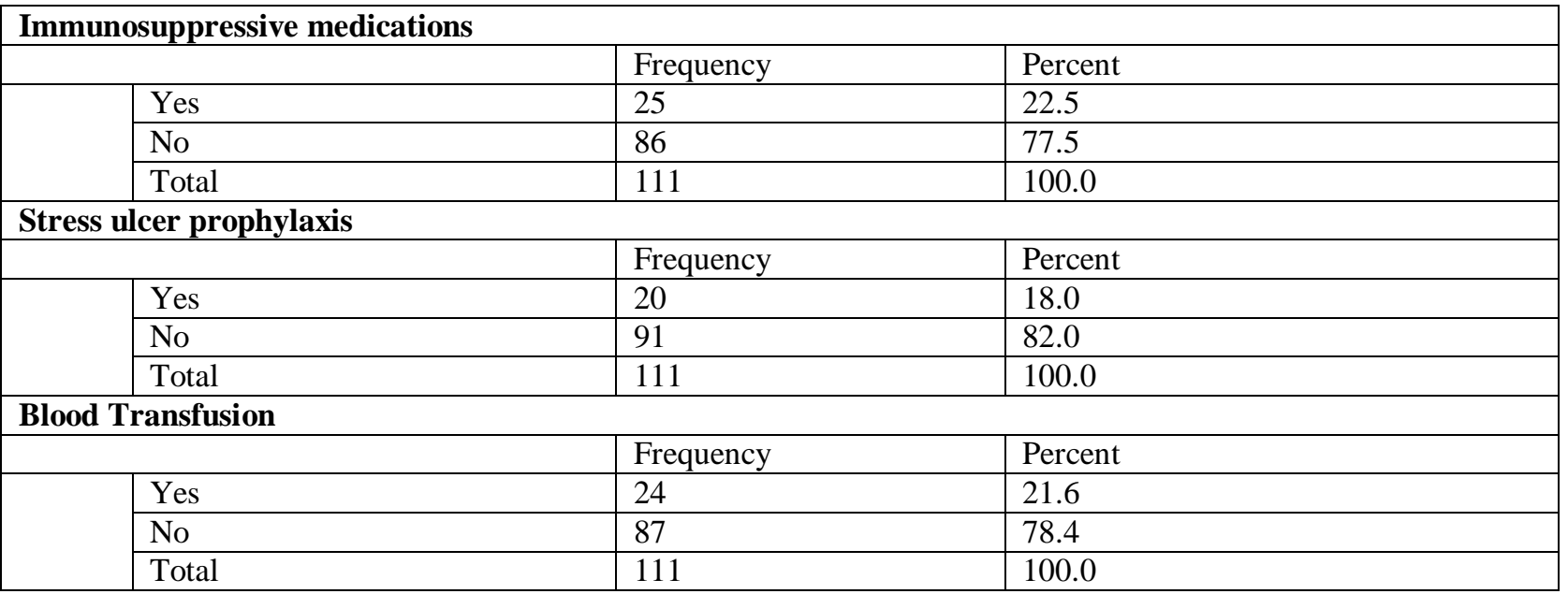




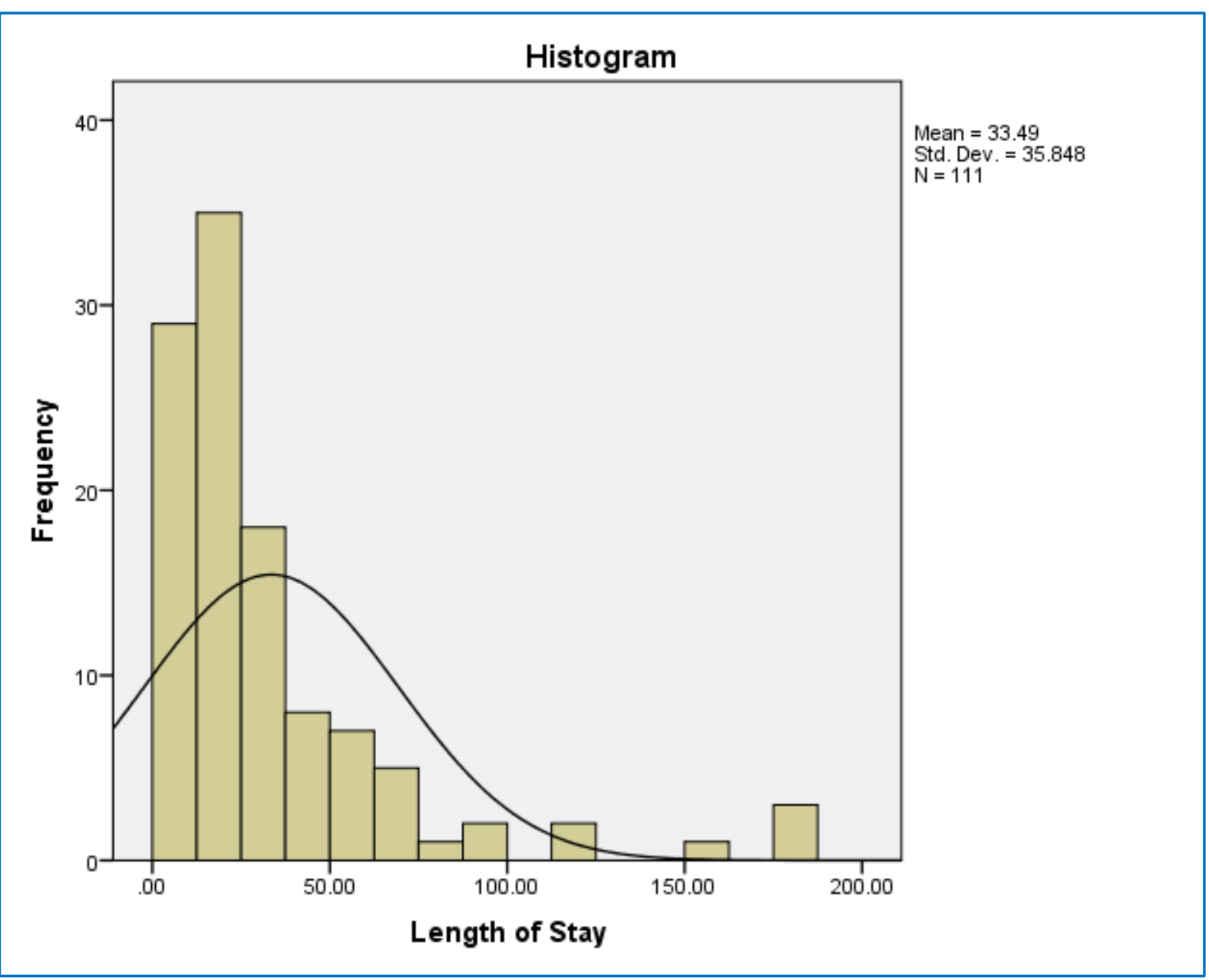

Figure 1:-The length of stay ranged from 3 minimum to 180 maximum days with a mean of ( 34 +or- 36 ) days. The length of stay was not normally distributed as seen from the graph, therefore, main patients stayed between 0 and 70 days with the median of 21 days.

Table 8:- The outcomes.

\begin{tabular}{|l|l|l|l|}
\hline \multicolumn{2}{|l|}{ Outcome } & Frequency & Percent \\
\hline \multicolumn{7}{|l|}{} & Recovery within 1 week & 64 & 57.7 \\
\cline { 2 - 4 } & Recovery > 1 week & 38 & 34.2 \\
\cline { 2 - 4 } & Recovery with comorbidities & 5 & 4.5 \\
\cline { 2 - 4 } & Mortality & 4 & 3.6 \\
\cline { 2 - 4 } & Total & 111 & 100.0 \\
\hline
\end{tabular}

\section{Discussion:-}

The goals of the study were to know the most common organism that cause nosocomial infection, most common site of infection and the risk factors. Coagulase-negative staphylococci was the most common infection which present $(25.3 \%)$ of our samples.

Coagulase-negative staphylococci are part of normal flora of the human skin, and it can be transmitted throw any invasive devises to the blood and cause infection, that's why it'sthe most common infection in hospitals.

A study of 24,179 cases of nosocomial in 49 hospitals across the United States suggest that (31\%) of sample were coagulase negative staphylococci (11). 
But on the other hand, a study of 841 patients done in tertiary care teaching hospital showed that klebisiella pneumonia was predominant (12).

The data indicate that the UTI is the most common site of infection.

A study done in United States, 110709 pediatric patients with 6290 nosocomial infections suggest that the blood stream infection is more frequently than UTI (13).

Prolonged hospital stay and frequently used of invasive devices with poor hygiene can cause hospital acquired infection and may cause complication such as sepsis and maybe death .

Immunosuppressive medication,central venous catheter and nasogastric tubeare most common predisposing factors. Study of 911 cases was performed at St Louis Children's Hospital, showed thatpatients with bloodstream infection were more likely to have multiple central venouscatheters (14).On the other hand, in Egypt, there is a study conducted in devises associated infection, they found that the Patients who are on mechanical ventilation device, central venous line, or urinary catheter are at higher risk to develop NI (6). But in our study we found that Patients who are on central venous line, peripherally inserted catheter and Nasogastric tube are at higher risk to develop NI.

\section{Conclusion:-}

Infant patients are more reliable to get a Nosocomial infection than the other pediatric age groups. In this study, the UTI is the commonest type of infection. Gram negative organisms are the most common to cause an NI but, the Coagulase-negative staphylococci is the common organism. Immunosuppressive medications, Central venous catheter and Nasogastric tube are the three most potential predisposing factors. The majority of patients recovered within one week.

\section{Perspectives:-}

We believe that we need further similar studies with multicenter and larger sample size. Also, a control group that involves patients with a non-nosocomial fever might help to understand the possible risk factors for the development of nosocomial infection.

\section{References:-}

1. Inweregbu K, Dave J, Pittard A. Nosocomial infections. ContinEducAnaesthCrit Care Pain. 2005;5(1):14-17.

2. Urrea M, Rives S, Cruz O, Navarro A, José García J , Estella J. Nosocomial infections among pediatric hematology/oncology patients: Results of a prospective incidence study. American Journal of Infection Control. 2004;32(4):205-208.

3. Singhi S, Ray P, Mathew J, Jayashree M, Dhanalakshmi. Nosocomial bloodstream infection in a pediatric intensive care unit. Indian J Pediatr. 2008;75(1):25-30.

4. Tantracheewathorn T, Vititpatarapak N, Phumisantiphong U. Epidemiologic study of nosocomial bacterial infection of pediatric patients at BMA Medical College and Vajira Hospital. Journal of the Medical Association of Thailand, Chotmaihetthangphaet [Internet]. 2007 [cited 3 March 2016];90(2):258-65.

5. Becerra M, Tantalean J, Suarez V, Alvarado M, Candela J, Urcia F. Epidemiologic surveillance of nosocomial infections in a pediatric intensive care unit of a developing country. BMC Pediatrics. 2010;10(1):66.

6. Rasslan O, Seliem Z, Ghazi I, El Sabour M, ElKholy A, Sadeq F et al. Device-associated infection rates in adult and pediatric intensive care units of hospitals in Egypt. International Nosocomial Infection Control Consortium (INICC) findings. Journal of Infection and Public Health. 2012;5(6):394-402.

7. Ben Jaballah N, Bouziri A, Kchaou W, Hamdi A, Mnif K, Belhadj S et al. Épidémiologie des infections bactériennesnosocomialesdans une unité de réanimationnéonatale et pédiatriquetunisienne. Médecineet Maladies Infectieuses. 2006;36(7):379-385.

8. Raymond JAujard Y. Nosocomial Infections in Pediatric Patients: A European, Multicenter Prospective Study . Infection Control and Hospital Epidemiology. 2000;21(4):260-263.

9. Abdel-Fattah M. Surveillance of Nosocomial Infections at a Saudi Arabian Military Hospital for a One-Year Period. International Journal of Infectious Diseases. 2005;12:e369-e370. 
10. Jackowska T, Pawlik K. Prevention of nosocomial infections in the pediatric ward - own experiences. - PubMed - NCBI [Internet]. Ncbi.nlm.nih.gov. 2015 [cited 6 June 2016]. Available from: http://www.ncbi.nlm.nih.gov/pubmed/26384127

11. Wisplinghoff H, Bischoff T, Tallent S, Seifert H, Wenzel R, Edmond M. Nosocomial Bloodstream Infections in US Hospitals: Analysis of 24,179 Cases from a Prospective Nationwide Surveillance Study. 2004.

12. Singhi, Ray, Mathew, Jayashree, Dhanalakshmi. Nosocomial bloodstream infection in a pediatric intensive care unit. - PubMed - NCBI [Internet]. Ncbi.nlm.nih.gov. 2008 [cited 19 December 2016]. Available from: https://www.ncbi.nlm.nih.gov/pubmed/18245931

13. Richards M, Edwards J, Culver D, Gaynes R, System t. Nosocomial Infections in Pediatric Intensive Care Units in the United States [Internet]. Pediatrics.aappublications.org. 1999 [cited 19 December 2016]. Available from: http://pediatrics.aappublications.org/content/103/4/e39.short

14. Yogaraj J, Elward A, Fraser V. Rate, Risk Factors, and Outcomes of Nosocomial Primary Bloodstream Infection in Pediatric Intensive Care Unit Patients. 2002. 